\title{
Salient Key Features of Actual English Instructional Practices in Saudi Arabia
}

\author{
Khalid Al-Seghayer ${ }^{1}$ \\ ${ }^{1}$ Saudi Electronic University, Saudi Arabia \\ Correspondence: Khalid Al-Seghayer, P.O. 105487 Riyadh 11646, Saudi Arabia. E-mail: alseghayer@yahoo.com
}

Received: February 27, 2015 Accepted: March 30, 2015 Online Published: May 28, 2015

doi:10.5539/elt.v8n6p89 URL: http://dx.doi.org/10.5539/elt.v8n6p89

\begin{abstract}
This is a comprehensive review of the salient key features of the actual English instructional practices in Saudi Arabia. The goal of this work is to gain insights into the practices and pedagogicapproaches to English as a foreign language (EFL) teaching currently employed in this country. In particular, we identify the following central features of the Saudi English teaching portfolio: a) an overview the features of EFL teaching in Saudi Arabia, b) features of the actual teaching of the four macro-language skills, c) features of the actual teaching of language-related skills, and d) features of evaluation methods. By putting forth an inclusive, aggregate picture of the actual English teaching practices implemented in Saudi EFL classrooms, we hope to reveal and elucidate the total reality of the major modes of EFL pedagogic practices and assessments in Saudi schools.
\end{abstract}

Keywords: assessment measures, instructional practices, four macro language skills, language-related skills, pedagogic approaches

\section{Introduction}

In recognition of its increasingly significant importance, countries all over the globe have selected English as the first-rate foreign language to teach in their educational systems; in this approach, Saudi Arabia, which was founded in 1932, is no exception. The introduction of English is more noticeable in Saudi Arabia than elsewhere, due to the sustained rapid advancement and modernization that the country has gone through in the past and continues to experience. Saudi Arabia has entered the economic, educational, and political theaters of the world. As a result, while absorbing what the world at large has to offer, successful enterprise requires the Saudi people to be equipped with the means of conveying Saudi Arabia's vision and needs to the outside world. This task entails a profound command of the international language, English.

English has a strong and palpable presence in the Saudi educational system due to a range of considerations. It is the sole foreign language that is taught in Saudi public schools. English is also taught in private schools, universities, and a variety of industrial and government institutions. At the primary, intermediate, and secondary levels, and at all grade levels in private schools, English is also taught as a core subject.In addition to being taught in public educational establishments, Englishis taught in all Saudi universities, either asan elective subject or as a major field of study. Even students who are not English majors are required to take an introductory English course. Most university departments use English as a medium of instruction in areas suchas science, medicine, engineering, allied health, and other technical subjects.

Several salient features distinguish and shape the Englishinstructional practices used in the Saudi educational system, in general and in public education, in particular. The primary aim of this paper is to survey the teaching of English in Saudi schools. This comprehensive profile describes all aspects equated with the current process of teaching English in Saudi Arabiain detail, with the hope of drawing an accurate picture that captures the contemporary teaching practices for the world language of the modern era. We wrote this paper with the intention of exploring current English language teaching practices in the Saudi context.

The centrallydescribed feature of the portfolio is the provision of an overview of the features of English as a foreign language (EFL) teaching in Saudi Arabia. It then proceeds with an in-depth description and discussion of teaching English in Saudi schools with respect to features of the actual teaching of the four macro language skills, the features of the actual teaching of language-related skills, and the features of the current assessment methods. The aim is to identify and provide an in-depth description and discussion of current English instruction in Saudi 
EFL classrooms across the aforementioned areas, rather than propose some suggestive accounts to change the direction of the classroom practices implemented in Saudi EFL classes. Therefore, this paper maybe more descriptive in nature,with an occasional critical analysis brought to bear as the issues under discussion require, and is concerned more with identifying the actual English instructional practices than with anything else.

\section{Overview of the Features of EFL Teaching in Saudi Arabia}

Current traditional methods used to teach English in Saudi Arabia mostly follow audio-lingual and grammar-translation methods. Saudi English teachers employ a number of techniques to carry out these traditional teaching methods, including structural analysis, chorus work, answering questions, corrections, and translating texts. Additionally, reading and repeating passages, providing detailed language information, and practicing the formulaic use of translated chunks of language consume much of the teachers' time and efforts.

Students are passively attentive to their teachers' explanations of grammar, as the center of instruction, or presentation of vocabulary. Then, the teachers instruct their students to memorize words and grammatical rules and subject the students to drills in reading passages aloud, translating words and sentences, and copying the taught vocabulary and other newly introduced language items from the blackboard into their notebooks. The teachers also engage them in extensive mechanical drills, mostly to practice the taught language patterns. The main focus of teaching the skill of writing is the final production of the task of writing, alongside the linguistic features and sentence-level construction (Al-Hazmi, 2006). Khan (2013) indicated that the major focus of EFL instruction is reading and writing skills, rather than the other two macro skills: listening and speaking; Saudi EFL instructors place less importance on listening and speaking skills. Equally, Ahmad (2014) has contended that Saudi EFL teachers consider grammar to be the most crucial aspect of the English language to master.

Teachers often use Arabic, their mother tongue and the only indisputable officially recognized language in the state, when teaching and managing English classrooms, or they depend on translations (Al-Seghayer, 2014). Alshammari (2011), Kharesheh (2012), and Mahmoud (2012) have attributed Saudi students' deficiencies in the four basic language skills to the extensive use of Arabic in the classroom. This excessive use of Arabic has remained unchanged, as the results of Al-Nofie's (2010) studyindicated: Saudi EFL teachers (80\%) and learners (70\%) alike expressed a positive attitude toward using Arabic as a medium of instruction in the English classroom. The three most commonly cited reasons for the continued use of Arabic in English classes were a) explaining new words, b) checking students' understanding, and c) explaining grammatical concepts. Machaal's (2012) findingsshowed that $77 \%$ of teachers who participated in the study were in favor of the use of Arabic in EFL classes; Arabic was mainly (86\%) used to explain English vocabulary and translate English words.

A visitor to an English class in Saudi Arabia today would conclude that Arabic and translation into Arabic dominate the interactions between teachers and students. In an English classroom, Saudi English teachers tend to speak Arabic more than is necessary and use Arabic more than English when giving instructions, providing explanations of language items, and conducting class activities. Students prefer to use Arabic when they take the initiative or ask questions.

Al-Mazroou (1988) made another valid observation concerning Saudi teaching methods. The system of teaching English in Saudi Arabia is such that teachers are reluctant to propose their own instructional activities, fearing that they might distract students' attention from the established lessons and cause them to fail the final exam. In other words, teaching centers on the development of grammatical competency, with only marginal attention given to communicative competency and discourse or sociolinguistic and strategic competencies. Teachers do not teach students techniques that enable them to interpret spoken and written forms of English. They do not teach students when to say what to whom or how to use the language in different ways according to the sociolinguistic situation in which they find themselves. They also do not equip their students with techniques they could employ in the case of a communication breakdown. Importantly, most Saudi English teachers do not use teaching aids or authentic supplementary materials in the English classroom. Instead, they tend to employ only the course textbook and the blackboard.

Based on researchers' numerous visits to public schools, most teaching is either text- or teacher-centered, with the students' active participation being limited to parrot-like repetition of chunks of text from a set of books read aloud by the teacher. Furthermore, classroom activities are broken down as follows: grammar (32\%), translation (30\%), reading (17\%), writing (12\%), and speaking (9\%). Hence, the students' knowledge of English is indeed more formal than communicative because the actual teaching of English focuses almost exclusively on the mastery of linguistic patterns without sufficient attention being paid to their use in communicative situations. Most Saudi EFL teachers are more comfortable with and more able to perform effectively by using this non-communicative approach. Therefore, because grammar and word recall dominate class instruction and are learned separately from 
the situations in which they are used, it is reasonable to suggest that English is taught as a content subject or body of conceptual knowledge,which in turn makes English class dull and students often appear bored, off-task, and unruly.

One may attribute the predominance of this approach to both a main cause and secondary causes. Primarily, a focus on knowledge transmission characterizes teaching and learning in Saudi EFL classrooms, where teachers largely dominate classroom interaction. Thus, a teacher-centered transmission model guides English teaching. During English lessons, teacher-fronted presentations and explanations of new language items are predominant, providing little opportunity for students' input. Therefore, one would view a Saudi EFL teacher as a material presenter and content demonstrator, not as a manager of language learning situations (Rahman \& Alhaisoni, 2013). Adherence to such models counteracts any attempt to shift the English teaching paradigm toward a student-centered approach, wherein a teacher serves as a facilitator rather than a controller of the classroom, takes a communicative approach, and employs less-constrictive alternative teaching methods.

Other reasons for or causes of the prevalence of traditional teaching methods and the consequent failure to work toward the goal of developing Saudi EFL students' communicative proficiencyinclude a lack of clear instructional materials on how to implement newer methods, inadequate training of EFL professionals, and the various responsibilities assigned to EFL teachers.

Saudi English teachers, as the front-line players, do not receive documented guidance on how to integrate communicative language-teaching techniques into their classrooms, nor do they receive any training on how to translate the principles of the communicative approach into classroom practice. This situation may exist because this particular method requires skills that the majority of Saudi English teachers lack, such as a thorough command of English, especially with reference to the language needed for various types of classroom activities, such as eliciting ideas and contributions from the students, giving instructions, explaining, giving feedback, and dealing with errors (Al-Seghayer, 2014). Saudi English teachers also lack the ability to prepare appropriate communicative teaching materials. On a similar note, there appears to be a high level of dissatisfaction among Englishteachers with the training that has been made available to them and with the textbooks they are required to use.

All of the above issues seem to be true of Saudi English teachers, as Al-Mohanna (2010) has contended. After visiting nine secondary schools, in which he observed 18 English teachers in their classrooms and interviewed 40 English teachers, Al-Mohanna arrived at the conclusion that Saudi English teachers are not communicatively oriented, because they have inadequate theoretical background knowledge, which could otherwise guide their teaching practice toward such a teaching approach.

The learning environment also contributes to this trend, as is reflected by class size. This is particularly true where the teacher-student ratio is high (40-50 students per class). Communicative activities are difficult to conduct in Saudi English classrooms that are not designed to accommodate a large number of students comfortably. Saudi English teachers often complain that small, overcrowded classrooms prevent them from giving their students equal opportunities to practice the language. Furthermore, teachers have pointed out that, given such circumstances, communicative activities in the classroom become shallow and difficult to accomplish. In large classrooms, teachers often find it difficult to attract students' attention to class activities, meet their individual interests and needs, and maintain good discipline (Al-Seghayer, 2011).

Another causative factor that leads teachers to revert to traditional teaching methods is that almost all teachers' timetables are heavily loaded with academic and administrative responsibilities. Each teacher in Saudi Arabia teaches 24 periods per week (six classes), and the average teacher teaches approximately 180-200 students. English teachers, with only three or four hours per week allotted for each class, experience pressure to cover the materials prescribed in voluminous textbooks and packed curricula within a limited period. Keeping pace with the tight curriculum schedule is a priority in the EFL classroom.

In addition, teachers must devote time to preparing or planning daily lessons, preparing and grading exams, and grading homework assignments. They often have to decipher illegible handwriting in the student notebooks that they correct daily and deal with hyperactive youngsters. Furthermore, teachers are required to engage in many extracurricular activities. Therefore, Saudi EFL teachers are saddled with an excessive workload that causes work-related stress when they implement their daily chores. Most importantly, the additional work encroaches on the time needed for teaching and adversely affects teachers' performance in the classroom. It also makes teachers more inclined to resort to traditional teaching methods rather than use a communicative teaching approach.

Shah, Hussain, and Nasseef (2013) proposed that additional factors shape Saudi English instructional practices, specifically, the restrictions imposed by the Ministry of Education (MOE) on how to teach and what to teach. At each grade level, English teachers receive an identical syllabus, with guidelines and deadlines that the MOE 
requires them to apply and follow. Additional reasons for the prevalence of traditional teaching methods include students being uncomfortable with expressing ideas that differ from the group's ideas or those of the previous speaker; teachers perceiving learning as the rote memorization of grammar and vocabulary; teachers structuring classes around their presentation of information that students must memorize, with almost all interactions involving students answering questions posed by the teacher; teachers undervaluing the practice of questioning and analyzing; English teachers' perceptions or beliefs informing their knowledge about teaching English and shaping what they do in the classroom; and schools adopting an exam-oriented culture.

When combined, these problems have caused Saudi EFL learners to adopt a passive approach to learning. The examination system is achievement-oriented rather than performance-oriented, leading to an emphasis on grades rather than fluency or proficiency. Due to such practices, Saudi EFL teachers remain facilitators of examinations in English, rather than facilitators of linguistic or communicative proficiency. Teachers also abandon stimulating interactive activities in the English classroom, such as games, role-playing, and talk-based communicative activities. This also discourages teachers from attempting to engage their students in authentic communicative situations, such as exchanging information, arranging meetings, solving problems, and engaging in daily business and shopping transactions.

English teachers themselves play a role in this practice and tend to prefer traditional teaching methods to a communicative approach or sound, effective teaching methods. They strongly believe that the top priority in teaching English is teaching grammar rules and vocabulary. From their perspective, grammar rules and vocabularyshould be the starting point of all instructional aims that are followed in the English classroom.

These facts show that switching to a different style of teaching requires more effort than replacing textbooks, selecting textbooks that are more communicative, or orienting teachers to use different teaching approaches. Rather, switching teaching styles entails creating a method of teaching that is compatible with the setting in which it is used as well as considering a different pedagogic emphasis.

On this basis, a number of factors seem to determine the process and the current traditional practices of teaching English in Saudi schools. These factors fall into two major categories: internal factors and external factors. The internal factors are, for the most part, the low language proficiency level of a substantial number of Saudi English teachers, misconceptions about communicative language teaching, and teachers' beliefs and attitudes toward alternative, innovative language teaching methods. The external constraining factors are detectable in the teacher-centered transmission model and the lack of instructional materials and guidance on how teachers should integrate communicative language teaching techniques into their classrooms. Other external factors are the outcomes of the inadequate pre-service and in-service training opportunities and provision of ongoing support and professional development for Saudi English teachers, ineffective and old-fashioned teaching methods, the number of educational and non-educational responsibilities that schools assign to English teachers, and the unavailability of the required resources for large class sizes (Al-Seghayer, 2014; Bahanshal, 2013). The examination-oriented system, or high-stakes tests, and textbook-driven pedagogy are also external factors, alongside time constraints and students' English proficiency.

\section{Features of the Actual Instructional Practices in Saudi EFL Classrooms}

Unlike the traditional division of language skills instructioninto particular skills, the actual teaching English as foreign language (EFL) instructional practices in Saudi EFL classrooms adheres to an integrated, holistic teaching method that is drawn from a skills-based language teaching approach. This approach entails teaching major language skills and sub-skills together. The assumption informing this approach is that each skill will be developed in combination with other skills to cover all language functions and achieve the goal of teaching English for communicative purposes. To this end, in this part of the paper, we will identify the salient key features of the actual instructional practices for the four macro language skills of listening, speaking, reading, and writing, along with specific micro- or language-related skills, namely, grammar, vocabulary, and culture, in the Saudi context. In Saudi EFL classrooms, these macro and micro language skills are integrated consecutively intoeach 45-minute class period; each skill is allotted a designated portion of the class period, four times a week. Accordingly, we will identify key instructional practices for each individual skill and sub-skill separately to capture the reality of Saudi EFL classrooms.

\section{Features of the Actual Teaching of the Four Macro Language Skills}

\subsection{Listening}

During listening classes, Saudi EFL instructors employ instructional approaches that favor the development of bottom-up skills, primarily to aid students with lower English proficiency who need to expand their language 
repertoire. The instructors adopt bottom-up listening exercises or activities and tasks designed to enable students to recognize lexical, grammatical, and pronunciation features and language forms at the word and sentence level. Focusing on bottom-up processing skills, the instructors ask students to distinguish individual sounds, recognize word boundaries and stressed syllables, listen for intonation patterns and specific details, identify grammatical forms and functions, recognize contractions and connected speech, and recognize linking words and phoneme sequences as they circle the words they hear. Other popular traditional listening activities that focus primarily on bottom-up processing include dictation, cloze listening, text-based multiple-choice questions, and similar activities that require close and detailed recognition and input processing.

Unlike instructors in process-oriented classrooms, Saudi EFL instructors are in charge of everything and are in total control of classroom activities. To teach specific, isolated listening skills, they select input, design, and sequence listening activities; determine tasks; and decide what constitutes a correct response. However, Saudi instructors mainly test students' listening abilities instead of helping them to cultivate their listening abilities by teaching them effective listening comprehension strategies. According to Nurul Islam (2012) and Hamouda (2013), listening is the least understood aspect of language teaching in the Saudi English classroom and is, therefore, a neglected skill. Moreover, teacherspay limited attention to this particular skill when designing their lessons, perhaps because they assume that listening comprehension skills will develop naturally within the process of language learning.

\subsection{Speaking}

Instructors use various approaches and techniques to teach speaking skills in Saudi EFL classes, including direct approaches that focus on specific features of oral interaction (e.g., turn-taking, topic management, or questioning strategies) and drill-based or repetition-based methodologies (e.g., repeating after the teacher, memorizing a dialog, responding to drills, or answering questions). These approaches can all be classified as traditional methods of teaching speaking skills, none of which simulate real interaction or communication or engage students in meaningful speaking activities thatpromote speaking. Instead, these methods require students to repeat phrases verbatim and, as a result, fail to support the development of essential oral skills and communication strategies. Thus, such traditional teaching strategies do not provide opportunities for Saudi EFL learners to acquire each type of speaking skill. Additionally, they do not include different meaningful speaking activities such as role-playing, jigsaw tasks, conversations, group discussions, information gaps, and other game activities, as well as interviewing, storytelling, making small talk, ending conversations, narrating and describing pictures, reacting to what others say, andrecounting personal incidents and experiences. Saudi EFL learners, thus, are neither engaged in a real speaking environment, nor are theyintroduced to one.

According to Hamad (2013), several factors influence the speaking instruction practices in the Saudi context. First, many EFL instructors allow students to use Arabic. For instance, $80 \%$ of the participants in Abu-ghararah's (2014) study indicated that they mostly used Arabic with their English teachers during class time. Second, instructors do not encourage students to express their opinions in English; instead, they randomly select students to answer questions or express their thoughts on a given topic. Third, students receive very limited opportunities to speak Englishand the time devoted to speaking in class is not enough. Fourth, the speaking classes are relatively large, with more than 40 students in a class. Fifth, as was previously noted, these speaking classes do not include classroom speaking activities and tasks such as role-play, debates, discussions, presentations, cultural debate topics, and pair-speaking activities.

Many studies support Hamad's (2013) argument. According to Al-Twairish (2009), Saudi EFL classes devote a significant amount of time to learning and memorizing language forms at the expense of teaching speaking skills. Saudi English classes give more importance to grammar, reading, and listening skills than to speaking skills and continue to use traditional classroom speaking practices, especiallydrills, in which one person asks a question and another gives an answer (Khan, 2013). Accordingly, as Abu-ghararah (2014) found, Saudi students rarely practice speaking English in the English classroom, and speaking activities are limited to reading a text or answering the teacher's questions. On this note, about 70\% of the EFL instructors in Al-Ma'shy's (2011) study indicated that they did not encourage their students to speak English in the classroom or utilize different speaking activities, and $80 \%$ of the instructors admitted that they interacted with their students in Arabic.

\subsection{Reading}

Saudi EFL classrooms also struggle to teach reading skills and precise reading comprehension adequately (Albik, 2014). Reading aloud, wherein a student reads a text to the rest of the class, or different students take turns reading different parts of the text, occupies a major portion of the teaching time. According to Alshumaimeri (2011), oral reading is the most preferred reading method among Saudi English teachers. Alsamadani (2012) 
affirmed this position, stating that Saudi EFL teachers devote the designated class time to reading, practicing silent reading, and answering reading comprehension questions at the expense of teaching and practicing reading skills and strategies. Additionally, $75 \%$ of the EFL teachers in Alsamadani'sstudy indicated that they knew nothing about metacognitive reading strategies and were only aware of cognitive reading strategies. However, these teachers tended to avoid teaching cognitive reading strategies because they require tremendous effort and consume a significant amount of class time.

In the same vein, surveying in-service Saudi EFL teachers, Bamanger and Gashan (2014) identified scanning the text, reading the text aloud, explaining vocabulary items, translating words into Arabic, asking questions to check comprehension, and teaching students to guess the meaning of ambiguous vocabulary as common strategies used in the Saudi EFL classroom. The EFL teachers who participated in the study asserted that these were the most significant strategies in teaching reading skills to Saudi EFL learners. Likewise, Al-Rojaie (2011) found that oral reading instruction and decoding a passage word by word were common classroom reading practices. Favoring these practices, the Saudi EFL teachers in Al-Rojaie's study did not implement reading strategies such as detecting main ideas, activating students' prior knowledge, summarizing and retelling, or monitoring reading comprehension in the reading classes.AlNooh (2013) also identified oral reading as the most commonly practiced teaching method for reading skills and noted that the allocated class time of 45 minutes was not enough to teach L2 reading skills to Saudi secondary students.

\subsection{Writing}

The current practice of teaching writing skills in Saudi EFL classrooms focuses mainly on the final production of the writing task alongside the linguistic features and sentence level (Alnufaie \& Grenfell, 2012; Vanderpyl, 2012). Saudi teachers emphasize linguistic accuracy, which is at the forefront of their instruction, as well as proper grammar, accurate spelling, meaningful punctuation, and range in vocabulary and sentence structures. Current practice reflects a traditional teaching and product-based approach in whichSaudi teachers a) eliminate any interaction between the teacher and students or between students; b) approach writing as a linear process in which students are expected to follow fixed steps, such as pre-write, write, and re-write; and c) do not teach students to edit or revise, meaning the students show little flexibility in changing their original ideas. Furthermore, this approach involves several types of writing, including guidance, control, and assistance with questions to answer, a model to follow, an outline to expand, an incomplete piece of writing to complete, or an incorrect text to correct. Writing instructors also tend to ask students to write without planning or collecting related information. Further, these instructors provide the students with only authoritative feedback and minimal commentary, and are overwhelmed by the task of providing feedback and correcting students' writing. The instructors neglect the benefitsof teacher-student conferencing and peer feedbackand avoid utilizing various writing activities, such as writing in silence, journal writing, free writing, or reflection. Thus, writing instruction in Saudi EFL classrooms overstresses the final writing product and prioritizes accuracy, linearity, and prescriptivism.

A number of factors influence this use of traditional methods of writing instruction in Saudi EFL classrooms, including time constraints, large class sizes or overcrowded classrooms, teachers' lack of experience teaching L2 writing, and students' lack of ability to write in their own language, Arabic, and lack of adequate training in writing English. Additional factors that influence the learning outcomes include insufficient writing practice, instructors looking for errors rather than ideas, lack of feedback on content, and regarding only formally grammatically correct sentences (Huwari \& Al-Khasawneh, 2013). Javid and Umer (2014) attributed these factors to the dreadful writing teaching methodology used in Saudi English classrooms.

\section{Features of the Actual Teaching of Language-Related Skills}

\subsection{Grammar}

With respect to teaching grammar, a traditional or outdated approach dominates the actual grammar instruction practice in Saudi EFL classrooms. This approach follows the Presentation-Practice-Production methodology, which is known as the PPP model is akin to a rule-driven deductive approach. This model views grammar as a product that entails dividing language into segments and teaching them independently of one another. Using this approach, a teacher will present a language structure or tense (e.g., present simple) and allow the students to practice using it; the students must then produce an example of what he or she has learned. This approach to teaching grammar strives to encourage grammatical correctness and considers grammatical knowledge as a goal. Additionally, it adopts an overt and explicit presentation of grammatical rules and emphasizes spoon-feeding over exploration. 
According to Assalahi (2013), form-focused grammar instruction is the core teaching strategy of grammar instruction in Saudi EFL classes. Grammar is taught in isolation and instruction focuses on rote rules and memorization, as well as adhering to explicit formal grammar instruction (Albalawi, 2014). In other words, as Al-Musharraf (2007) has argued, grammar is rarely taught communicatively in Saudi EFL classrooms.

With respect to actual practice, the time designated for grammar instruction in Saudi EFL classes, based on the researcher's frequent visits to Saudi English classrooms, is divided into three stages. In the first stage, the instructor introduces the new concepts directly. In the second stage, students practice the newly introduced grammatical rule by completing highly controlled practical exercises, such as fill-in-the-blank and mechanical drill activities, including transformation drills, substitution drills, and integration drills. In the final stage, the instructor may ask students to generate their own examples and share them with the class.

There are certain distinguishing features of grammar instruction in Saudi EFL classes. In particular, instructors a) teach grammatical concepts by using many separate examples that are not contextualized or involved in communicative tasks, b) emphasize the mastery of grammatical concepts under study, c) place limited emphasis on practice, d) refrain from incorporating the studied grammar rules into other language skills, e) use Arabic to simplify the rules for students and facilitate grammar learning, and f) focus on the correctness or accuracy of production. As this overall approach to grammar instruction strongly emphasizes accuracy, Zohairy (2015) summarized some of the features above by stating that the methods used to teach grammar in Saudi EFL classrooms aim to provide students with a detailed analysis of English grammar rules.

\subsection{Vocabulary}

Traditional and direct vocabulary teaching techniques also prevail in Saudi EFL classrooms. These techniques include having students a) match words to their definitions, b) fill in theblanks with suitable words, c) look up dictionary definitions, d) copy out definitions from a dictionary, e) write sentences for each word based on the definition information, f) write the L2 words along with their L1 definitions or translations, and g) present word lists for memorization. Oxford and Scarcella (1994) have categorized these traditional vocabulary activities and techniques as decontextualized activities that do not entail active engagement orgo beyond definition knowledge. Using these techniques, Saudi EFL instructors present vocabulary items in controlled vocabulary-learning tasks, such as word lists, flash cards, and dictionary look-up activities, as well asunder studying situations that lack any communicative value. These techniques reflect unplanned and unsystematic vocabulary teaching activities in which students ask for the meaning of unknown vocabulary items and instructors provide the meaning. Even though instructors devote a considerable amount of instructional time to explaining and defining terms, this approach to vocabulary instruction is haphazard and lacks pre-planning. Teachers expect their students to acquire the target vocabulary items on their own without much guidance or explicit strategy instruction, provision of opportunities to learn vocabulary through context, or help with learning specific strategies for acquiring words.

In Al-Zahrani's (2011) study, such ineffective vocabulary instruction led to low vocabulary achievement among Saudi EFL learners. In particular, Alqahtani (2009) highlighted several unproductive practices used in Saudi EFL classrooms, such as teachers introducing words in lists rather than in context, students learning vocabulary by rote, and teachers asking students to write one-word answers to questions that require complete sentences. To improve vocabulary instruction, Al-Mohanna (2010) proposed that students should copy vocabulary items in their notebooks and perform various exercises, such as matching words. Overall, the actual vocabulary instruction in Saudi EFL classrooms does not considergoals, vocabulary-learningstrategies, or the benefits of more precise teaching techniques.

\subsection{Culture}

Cultural awareness is a severely neglected feature of Saudi English curriculum. To be more precise, culture is meagerly taught in the Saudi EFL classroom. Instructors neglect incorporating the cultural elements of English into EFL lessons because some EFL instructors, parents, and students perceive teaching cultural values as a form of cultural invasion or, more accurately, a form of linguistic globalization that emanates from cultural globalization.The fear is that teaching Western values or the Anglo-American culture to Saudi students will alienate them from their own cultural values through the non-representation of their context and will erode their identity. Those opposed to teaching English culture in Saudi Arabia call for including only Islamic and local cultural values in English textbooks (Al-Seghayer, 2011, 2013). Accordingly, there are no overt, explicit courses on developing cultural awareness in the Saudi EFL curriculum. Additionally, culture is not embedded in the language teaching materialswithout rereading the impossibility of teaching English without its cultural base, as language and culture are inextricably linked. 
Ahmad and Shah (2014) confirmed that many Saudi students and their parents have registered complaints about the inculcation of culturally inappropriate materials and the use of English textbook content published by international publishing companies in some Saudi language institutions. According to Aldosari (2013) and Alsamani (2014), instructors may avoid or fail to integrate cultural aspects of English-speaking countries in the microcosm of the Saudi EFL classroom fora number of reasons, including limited knowledge of the target culture and the fear of teaching or introducing cultural values, specifically those contrary to local customs, that may impede cultural teaching in the Saudi community. On this note, Alfahad (2012) attested that English is taught with greater reference to local Saudi cultural models than totargeted Western cultural values, and classroom activities draw more on Saudi culture. Furthermore, the fact that religious values are seen as integral to cultural practice informs teachers' views.

\section{Features of the Actual Evaluation Methods}

Further salient key features of Saudi EFL instructional practices can be found in the continued execution of traditional evaluation methods or assessment measures and arrangements, such as testing rote memory, knowledge of factual information, and the application of strict rules instead of testing critical thinking and higher-order comprehension skills with alternative assessment practices that elicit linguistic behaviors. In the EFL examination procedures currently executed in Saudi public schools, with the exception of grades 5 and 6 of elementary schools, the final English examination is divided into an oral test and a written test prepared by the English instructors following specific schema and guidelines developed by the MOE.

The oral test, which assesses students' speaking and listening skills, counts for $5 \%$ of the students' grade on the final examination. Not having official instructions on how to administer the oral test at hand, English teachers tend to ask students two or three easy questions and have them read aloud one or two sentences chosen from the textbook. As a result, teachers do not assess students on different aspects of the English language, such as pronunciation, fluency, use of lexis and grammar, and intelligibility. Teachers have no other options because of the limited time they have with the large number of students (40-50) in their classes. Such practices create a dilemma in the long term regarding teaching English in Saudi schools, in general, and teachinglistening and speaking skills, in particular. Students undervalue speaking and listening skills because of the small fraction of points allotted to these two skills on the final exam, compared to other language skills that comprise up to $25 \%$ of the final examination marks and because they are not paired with a written exam. Hence, the significance of the English oral test has been reduced drastically, and its prominence has faded away.

Scrutiny of a number of the English tests that are administered to students at the intermediate and secondary levels reveals an unpleasant picture. According to the official schema that has been developed, a written test must include a) composition questions, b) reading comprehension questions, c) dialog, d) grammar, e) information questions, and f) vocabulary questions. Composition questions require students to write about chosen topics. Lists of guided words that students can make use of when writing their essays often accompany these questions. Teachers take the topics, along with their lists, directly from intermediate and secondary English textbooks. Students memorize the topics discussed in class, along with their word lists, as they know in advance that the test will ask them to write an essay on one of the covered or discussed topics.

Teachers use the same practice and procedure for the reading test. Rather than testing their students on similar reading texts, English teachers test the students' comprehension of studied reading passages that are selected from the students' textbooks. The constructed reading comprehension test questions often do not require a genuine understanding of the passage, as they contain response cues; do not cover wide aspects of the information presented in the reading passage; and do not ask high-level questions or test the skill of inference. Instead, the questions are indirect, controlled test item types.

The tests present the dialog questions in the same manner. The teachers test their students on incomplete dialog taken from their textbooks and ask them to complete it. The grammar, information, and vocabulary questions are either fill-in-the-blank questions, true or false questions, short-answer questions, or multiple-choice questions. In developing questions for these parts, the English teachers select material from grammar, information, and vocabulary exercises in the textbooks. Constructing English tests in this manner simply encourages students to memorize lexical and structural items and, thus, fails to reveal the students' genuine ability in using those items in real-life situations that the students might encounter.

Al-Seghayer (2011) attributes the poor quality of the English tests developed in Saudi schools to four main factors. First, Saudi English teachers often have scant training opportunities in constructing and developing language tests, in general, and appraising learners of English in particular. Graduates of English departments take only one class on language testing, which focuses mainly on theoretical issues that are central to language testing at the expense 
of providing practical consideration or, more precisely, hands-on opportunities to develop actual English tests. As a result, most English teachers are not in a position to develop tests that accurately measure the language ability of their students, interpret and explain the results of the administered tests, or, consequently, make the correct decisions based on the obtained results. Additionally, they are not aware of some testing issues, such as validity and reliability.

Second, a substantial number of currently employed English teachers are college of arts graduates, where language testing is not one of the required courses in the plan of study. Third, the MOE imposes a schema on English teachers that they must follow when designing written English tests. Finally, the fear of being questioned by school administrators and supervisors about poor test results and students' low proficiency may lead Saudi English teachers to construct their exams in such a way as to enable their students to successfully pass the tests, although these results do not genuinely reflect the students' end-of-semester achievement or their real language ability. The dominance of an "exam-oriented" culture makes teachers do their utmost to prepare students for the final examinations and, therefore, concentrate on the areas and information that the tests will cover. It is as if the number of students that pass is the main concern.

Alsamaani (2014), who undertook the task of examining the language testing practices in EFL programs in Saudi universities, investigated the lack of adequate training in language test construction. Fifty English Saudi teachers from 12 intermediate public schools in the Qassim region took part in this study, responding to a task-based self-critique of classroom assessment knowledge and skills, thinking aloud protocol, and assessment training needs questionnaire. The results indicated that the participants had minimal training on constructing language tests. The author attributed this result to the fact that more than half of the newly employed Saudi English teachers are unqualified in the design and evaluation of EFL tests and are unaware of the different aspects associated with assessment.

\section{Conclusion}

This comprehensive account provides a glimpse of the English teaching practices that are currently being used in Saudi classrooms. As the in-depth description and discussion of actual English teaching practices in Saudi schools illustrate, current practicesdo not reflect cutting-edge second-language acquisition and teachingtheory, current trends in English teaching practices, or modern assessment approaches. Furthermore, they are not informed by the best practices, the most effective approaches to teaching EFL, or the most prominent instructional standards in the current field of English teaching. Instead, this superficial survey reveals that traditional language teaching methods, which divide English into subsets of discrete skills and areas of knowledge, thus dealing with skills in isolation, dominate the English teaching practices in Saudi EFL classrooms. Accordingly, there is an enormous gap between the recommended pedagogic approaches and the actual practices in Saudi English education, leaving the pedagogic implications of Saudi English with increasingly intractable problems.

To address these current issues, the Saudi MOE should redirect its recruitment policies to enforce strict requirements for English competency and teaching ability. Several measures need to be considered to ensure the quality and competence of EFL teachers and enhance the quality of English instruction that Saudi students receive. First, efforts should be made to develop a state licensing system or a tiered licensing system to certify novice English teachers. Such a system would strengthen English teaching as a profession, enhance the professional skills of Saudi English teachers, and even regain the public's trust in the English teachers employed in Saudi schools. Earning a beginner's license should require passing a test on subject matter knowledge, as well as a test on pedagogic knowledge. In addition, to teach English, instructors should be required to attend a mentoring and induction program or participate in professional development opportunities. In particular, college of arts graduates, whose English departments focus on English literature and neglect English methodology courses, should be required to take some methodology courses prior to becomingan English teacher.

Moreover, recruitment should adopt an increased focus on the evaluation of English communication abilities and institutions should constantly implement work assessments or ongoing teacher evaluations to evaluate teachers' English proficiency. Additionally, prospective teachers should be required to score within a certain range on standardized proficiency examinations such as the TOEFL, IELTS, and TOEIC to ensure that they have the required English proficiency levels. With the implementation of these suggestions, rigorous standards would be set and maintained for entry into the EFL profession in Saudi Arabia, and English teachers would be held to those standards. 


\section{References}

Abu-ghararah, B. (2014). Problems with speaking activities in the Saudi EFL classroom. Arab World English Journal, 5(4), 276-287.

Ahmad, A. (2014). Kumaravadivelu's framework as a basis for improving English language teaching in Saudi Arabia: Opportunities and challenges. English Language Teaching, 7(4), 96-110.

Ahmad, H., \& Shah, S. (2014). EFL textbooks: Exploring the suitability of textbook contents from EFL teachers' perspective. VFAST Transactions on Education and Social Sciences, 5(1), 12-20.

AlAbik, W. (2014). Assessment of reading comprehension of Saudi students majoring in English at Qassime University, Saudi Arabia. Studies in Literature and Language, 9(1), 155-162.

Albalawi, S. (2014). Using media to teach grammar in context and UNESCO values: A case study of two English teachers and two students for Saudi Arabia (Unpublished master's thesis). Eastern Washington University, Cheney, Washington.

Aldosari, H. (1013). Integrating culture learning into foreign language education. Umm Al-Qurma University Journal of Languages and Literature, 11, 10-42.

Alfahad, A. (2012). Saudi teachers' view on the appropriate cultural model for EFL textbooks: Insights into TESOL teachers' management of global cultural flows and local realties in their teaching world (Unpublished doctoral dissertation). University of Exeter, Exeter, U.K.

Al-Ma'shy, A. (2011). Causes of EFL speaking weakness in Saudi Secondary Schools in Al-Gunfuthah City (Unpublished master's thesis). King Saudi University, Riyadh, Saudi Arabia.

Al-Musharraf, A. (2007). Teaching and assessing grammar in English primary stage classrooms that promote communicative language (Unpublished master's thesis). Imam University, Riyadh, Saudi Arabia.

AlNooh, A. (2013). The Effectiveness of reading techniques used in a Saudi Arabian secondary school classroom as Perceived by Students and Teachers: A Study of Methods Used in teaching English and their effectiveness. Arab World English Journal, 4(3), 331-345.

Alnufaie, M., \& Grenfell, M. (2012). EFL students' writing strategies in Saudi Arabian ESP writing classes: Perspectives on learning strategies in self-access language learning. Studies in Self-Access Learning Journal, $3(4), 407-422$.

Alqahtani, S. (2009). The role of suing reading stories techniques on teaching English vocabulary for EFL learners (elementary stage) in Saudi Arabia (Unpublished master's thesis). Imam University, Riyadh, Saudi Arabia.

Al-Rojaie, Y. (2011). Saudi EFL reading teachers' pedagogical beliefs and practice: A qualitative case study. Journal of Arabic and Human Sciences-Qassim University, 5(1), 1-19.

Alsamaani, A. (2014). Evaluating classroom assessment techniques of novice Saudi EFL teachers. Journal of Arabic and Human Sciences, 7(2), 63-81.

Alsamadani, H. (2009). The relationship between Saudi EFL college-level students' use of reading strategies and their EFL reading comprehension (Unpublished doctoral dissertation). Ohio University, Athens, U.S.A.

Alsamadani, H. (2012). Reading strategy instruction in Saudi schools. Journal of Language Teaching and Research, 3(5), 829-837.

Alsamani, A. (2014). Foreign culture awareness needs of Saudi English language majors at Buraydah Community College. English Language Teaching, 7(6), 143-153.

Al-Seghayer, K. (2011). English teaching in Saudi Arabia: Status, issues, and challenges. Riyadh, Saudi Arabia: Hala Printed Co.

Al-Seghayer, K. (2013, January 29). Teach us English but without its cultural values. Saudi Gazette, 11.

Al-Seghayer, K. (2014). The actuality, inefficiency, and needs of EFL teacher-preparation programs in Saudi Arabia. International Journal of Applied Linguistics \& English Literature, 3(1), 143-151.

Al-Seghayer, K. (2014). The four most common constraints affecting English teaching in Saudi Arabia. International Journal of English Linguistics, 4(5), 17-26.

Alshammari, M. (2011). The use of the mother tongue in Saudi EFL classrooms. Journal of International Education Research, 7(4), 95-101. 
Alshumaimeri, Y. (2011). The effects of reading method on the comprehension performance of Saudi EFL students. International Electronic Journal of Elementary Education, 4(1), 185-195.

Al-Twairish, B. (2009). The effect of the communicative approach on the listening and speaking skills of Saudi secondary school students: An experimental study (Unpublished master's thesis). King Saudi University, Riyadh, Saudi Arabia.

Al-Zahrani, M. (2011). The effectiveness of keyword-based instruction in enhancing English vocabulary achievement and retention of intermediate stage pupils with different working memories capacities (Unpublished master's thesis). Taif University, Taif, Saudi Arabia.

Assalahi, H. (2013). Why is the grammar-translation method still alive in the Arab world? Teachers'beliefs and its implications for EFL teacher education. Theory and Practice in Language Studies, 3(4), 589-599.

Bahanshal, D. (2013). The effect of large classes on English teaching and learning in Saudi secondary schools. English Language Teaching, 6(11), 49-59.

Bamanger, E., \& Gashan, A. (2014). In-service EFL teachers' beliefs about teaching reading strategies. English Language Teaching, 7(8), 14-22.

Hamad, M. (2013). Factors negatively affect speaking skills at Saudi colleges for girls in the south. English Language Teaching, 6(12), 87-97.

Hamouda, A. (2013). An investigation of listening comprehension problems encountered by Saudi students in the EL listening classroom. International Journal of Academic Research in Progressive Education and Development, 2(2), 113-155.

Huwari, I., \& Al-Khasawneh, F. (2013). The reasons behind the weaknesses of writing in English among Pre-year students' at Taibah University. English for Specific Purposes World, 38(14), 1-9.

Khan, I. (2013). Speaking skills and teaching strategies: The case of an EFL classroom. Elixir International Journal, 58(10), 14557-14560.

Kharesheh, A. (2012). Exploring when and why to use Arabic in the Saudi Arabian EFL classroom: Viewing L1 use as eclectic technique. English Language Teaching, 5(6), 78-88.

Machaal, B. (2012). Assessing the role of Arabic in Saudi EFL classes. In W. Al-Amri, H. Noor, \& I. McGee (Eds.), Saudi preparatory year English program: The future and beyond: student, teacher, pedagogy and curricular issues (pp. 54-85). Madinah, Taibah University.

Mahmoud, S. (2012). The effect of using L1 (Arabic language) in the L2 (English Language) classroom on the achievement in general English of foundation year students in King Abdulaziz University. Sino-US English Teaching, 9(12), 1734-1738.

Nurul Islam, M. (2012). An analysis on how to improve tertiary EFL students' listening skill of English. Journal of Studies in Education, 2(2), 205-214.

Oxford, R., \& Scarcella, C. (1994). Second language vocabulary learning among adults: State of the art in vocabulary instruction. System, 22(2), 231-243.

Rahman, M., \& Alhaisoni, E. (2013). Teaching English in Saudi Arabia: Prospects and challenges. Academic Research International, 4(1), 112-118.

Shah, S., Hussain, M., \& Nasseef, O. (2013). Factors impacting EFL teaching: Ann exploratory study in the Saudi Arabian context. Arab World English Journal, 4(3), 104-123.

Vanderpyl, G. (2012). The Process Approach as Writing Instruction in EFL English as a Foreign Language Classrooms (Unpublished master's thesis). SIT Graduate Institute, Brattleboro, Vermont, USA.

Zohairy, S. (2015). Applying DDL approach in teaching grammar interactively. Retrieved from https://www.academia.edu/8234438/Applying_DDL_Approach_in_Teaching_Grammar_Interactively

\section{Copyrights}

Copyright for this article is retained by the author(s), with first publication rights granted to the journal.

This is an open-access article distributed under the terms and conditions of the Creative Commons Attribution license (http://creativecommons.org/licenses/by/3.0/). 